\title{
Differences Among Health Care Settings in Utilization and Type of Physical Rehabilitation Administered to Patients Receiving Workers' Compensation for Musculoskeletal Disorders
}

\author{
Paul F. Beattie - Roger M. Nelson - Kevin Basile
}

Published online: 18 January 2013

(c) The Author(s) 2013. This article is published with open access at Springerlink.com

\begin{abstract}
Introduction There is a paucity of data describing the relationship between practice setting and the delivery of physical rehabilitation to injured workers. Purpose To determine differences in the number of visits, the number of treatment units, and the proportion of billing for physical agents over an episode of care between different practice settings' providing physical rehabilitation to patients receiving workers' compensation for a musculoskeletal problem. Methods A large administrative database was evaluated retrospectively. Practice settings were classified as physician office, corporate physical therapy clinic, occupational medicine clinic, hospital-based outpatient clinic, or private physical therapy practice. Results 70,306 subjects $(72.7 \%$ male; mean age $=44.6, \mathrm{SD}=$ 11.8 years) were included in this study. Corporate physical therapy clinics had the highest mean values for total visits $(13.1, \mathrm{SD}=12.7)$ and for total units $(66.8, \mathrm{SD}=85.5)$, and the lowest mean values for proportion of physical agents during the episode of care $(.22, \mathrm{SD}=.18)$. Occupational medicine clinics had the lowest mean values for total visits $(6.8, \mathrm{SD}=7.9)$ and for total units
\end{abstract}

\section{P. F. Beattie $(\square)$}

Doctoral Program in Physical Therapy, Arnold School of Public

Health, University of South Carolina, Columbia, SC 29208, USA

e-mail: pbeattie@mailbox.sc.edu

\section{R. M. Nelson}

Clinical Benchmarks, LLC, King of Prussia, PA 19406, USA

e-mail: nelson@lvc.edu

R. M. Nelson

Lebanon Valley College, Annville, PA 17003, USA

K. Basile

MedRisk, Inc., King of Prussia, PA 19406, USA

e-mail: kbasile@medrisknet.com
(30.4, SD $=36.5$ ), and the highest mean value for proportion of physical agents during the episode of care (.41, $\mathrm{SD}=.22$ ). When controlling for ICD-9-CM codes, bodypart treated, surgical status, and geographical region there were small changes in effect size; however, the significance and directionality of differences between practice settings were not changed. Conclusions There were significant differences in billing for physical rehabilitation services between practice settings for patients receiving workers' compensation. Corporate physical therapy clinics billed for more total visits and total units over an episode of care than did other practice settings; however they also billed for a lower proportion of physical agents indicating a greater use of those interventions supported by evidence-based guidelines (exercise and manual therapy) compared to other practice settings.

Keywords Musculoskeletal injury - Injured worker . Health services $\cdot$ Rehabilitation

\section{Introduction}

Musculoskeletal injuries are a primary reason for individuals to receive medical care covered by workers' compensation [1-4]. Physical rehabilitation is a frequent component of the non-operative, and post-surgical management of many people with these conditions [5-7]. Although the efficacy and effectiveness of many physical rehabilitation interventions for musculoskeletal disorders have been described, there is considerable debate regarding the optimal clinical setting in which these interventions should be delivered to injured workers [8-17]. For example, in the United States, workers' compensation can be billed for physical rehabilitation that is performed in a wide 
variety of settings including, but not limited to, a private physical therapy practice, a corporate physical therapy clinic, a hospital-based clinic, a physician's office or an occupational medicine clinic. It has been frequently argued that variations in the business model of these clinical settings may impact on the overall cost-value of physical rehabilitation care provided [8, 10, 11, 14, 15]. Proponents of this argument submit that certain clinical settings are more likely to "over-utilize treatments" by having the patient receive an excessive number of visits and treatment units [11, 14]. In addition, it has been argued, but not demonstrated, that certain clinical settings over-rely upon time-effective but poorly supported treatments such as "physical agents," i.e., electrotherapy, thermotherapy and hydrotherapy, rather than evidence-supported, but more time-intensive treatments such as exercise and manual therapy [14].

Despite the potentially important impact upon clinical practice guidelines and health-care policy, there is a paucity of published data addressing the role of the clinical setting in the utilization of physical rehabilitation and in the adherence to evidence-based guidelines for specific types of interventions used [18-20]. Clarification of the relationship of the clinical setting to the delivery of physical rehabilitation for injured workers would fill an important research gap and greatly assist in the development of conceptual models that would help to maximize the cost-value of care. The purpose of the current study is to determine differences in the number of visits, number of treatment units, and proportion of billing for physical agents over an episode of care between different practice settings' providing physical rehabilitation to patients receiving workers' compensation for a musculoskeletal problem.

\section{Methods}

\section{Study Design and Database Construction}

A retrospective, cross-sectional evaluation was performed using bill payment records de-identified to protect patient privacy. Subjects were included if they were at least 18 years of age, and had completed an episode of physical rehabilitation for a musculoskeletal problem covered by workers' compensation. The dataset was generated from the bill-pay activity resulting from 11 nationally based insurance carriers that cover workers' compensation, and represented claims from 49 of the 50 United States (Rhode Island has a different coding system than others and was not included) and the District of Columbia submitted between July 2009 and December 2011. All cases represented a single episode of care at only one facility for the present claim. Cases with more than one episode of care for their claim, or those who received care at more than one facility for their current claim were not included in the analysis. Billing was based upon dates of service; bundled billing was not used in this system.

\section{Measures}

\section{Dependent Variables}

Physical rehabilitation utilization was measured by the number of visits and the total number of units billed for during the episode of care. Physical rehabilitation treatments were identified using the Current Procedural Terminology (CPT) codes included within the 97000 series [21] (Table 1). The treatments were then classified into one of two categories. The first category was labeled "physical agents" and included treatments employing heat, light, sound or electricity. Common examples of physical agents include hot packs, laser, ultrasound and transcutaneous electrical stimulation (TENS) [22]. The second category was labeled "therapeutic procedures" and included treatments utilizing exercise or manual therapy (joint mobilization, manipulation or massage). The total units billed for physical agents during the episode of care were divided by the total treatment units billed for during the episode of care to provide a representation of the proportion of total treatment that was devoted to physical agents. The proportion of treatment not devoted to physical agents represented treatment with therapeutic procedures. For example, if the proportion of physical agents to total units was .30, this would indicate that $30 \%$ of the units billed during the episode of care where for physical agents and the remaining $70 \%$ were billed for therapeutic procedures.

\section{Independent Variables}

Physical rehabilitation practice settings were classified based upon billing records. Each claim was classified into one of the following: physician office, corporate physical therapy clinic, occupational medicine clinic, hospital-based outpatient clinic, or private physical therapy practice.

The primary diagnosis for which care was provided was identified by the International Classification of Disease, 9th revision [23], Clinical Modification (ICD-9-CM) code that was submitted by the provider during the initial evaluation by physical rehabilitation services. Because the large number of ICD-9-CM codes within the musculoskeletal domain resulted in a low number of responses for many categories we chose to collapse our classification to increase statistical power and interpretability. The collapsed classification included 5 categories that are similar to those described by Pendergast et al. [18] and included: 
Table 1 Physical therapy treatment procedures and their corresponding 97000 code classified as "physical agents" or "therapeutic procedures"

\begin{tabular}{llll}
\hline Physical agents & 97000 code & Therapeutic procedures & 97000 code \\
\hline Hot and cold packs & 97010 & Therapeutic procedure & 97110 \\
Electrical stimulation (unattended) & 97014 & Neuromuscular reeducation & 97112 \\
Paraffin bath & 97018 & Aquatic therapy & 97113 \\
Whirlpool & 97022 & Gait training & 97116 \\
Diathermy & 97024 & Massage & 97124 \\
Infrared & 97026 & Manual therapy & 97140 \\
Ultraviolet & 97028 & Therapeutic procedure (group) & 97150 \\
Electrical stimulation (attended) & 97032 & Therapeutic activity & 97530 \\
Iontophoresis & 97033 & Development of cognitive skill & 97532 \\
Contrast bath & 97034 & Sensory integrative techniques & 97533 \\
Ultrasound & 97035 & Self care/home management & 97535 \\
Mechanical traction & 97012 & Community/work reintegration & 97537 \\
Laser (unlisted modality) & 97039 & &
\end{tabular}

arthropathy (arthritis or joint problems), dorsopathy (spine or back disease), sprains or strains, fractures or dislocations, and other.

To provide additional information regarding the nature of subjects' clinical condition we also classed subjects based upon the location of the body-part (s) for which care was provided. This classification included the upper extremity, lower extremity, back, neck, hand or multiple body-parts. Subjects were further classified based upon the presence or absence of a surgical procedure associated with their claim as well as the geographic region of the United States in which they received care.

\section{Statistical Analysis}

The initial dataset was evaluated and those cases with missing values or primary ICD-9-CM codes that were not within the musculoskeletal domain were deleted. Remaining data were summarized and the distributions of dependent variables were checked for normality. Logarithmic transformations were made to non-normal distributions.

Differences in the distributions or frequencies of variables describing subject characteristics (age-groups, gender, chronicity (days from onset of symptoms to beginning of rehabilitation treatment), surgical treatment or not, history of a prior W/C claim, and ICD-9-CM classification) between practice settings were investigated using one-way analysis of variance (ANOVA) or Chi square analysis.

Unadjusted differences in the distributions of each of the dependent measures (total visits, total units, and units of physical agents/total units per episode) between practice settings were assessed using one-way ANOVAs with Schieffe post hoc analysis. Univariate, general linear model two-way ANOVAs were then used to evaluate the between-group differences for practice settings for each of the dependent measures, i.e. total visits, total units, and proportion of total treatment units devoted to physical agents when adjusting for diagnosis, the body-part that was treated, surgical status and geographic region in which care was provided. The alpha level for all comparisons was set at .01. All analyses were performed using IBM SPSS version 19.0 .

\section{Results}

\section{Sample Characteristics}

Claims from a total of 3,944 clinical facilities were included. The majority of clinical facilities were from private physical therapy practices $(\mathrm{n}=2,860,72.5 \%)$, followed by corporate physical therapy clinics $(\mathrm{n}=561,14.2 \%)$, physician offices $(\mathrm{n}=263,6.7 \%)$, hospital-based outpatient clinics $(\mathrm{n}=180,4.6 \%)$, and occupational medicine clinics $(\mathrm{n}=80,2.0 \%)$. The initial data set consisted of 76,667 subjects. Of that, 6,361 claims were deleted due to missing values or primary ICD-9-CM codes that were not within the musculoskeletal domain. That elimination resulted in a dataset of 70,306 subjects used for analysis. Of the 49 U.S. states and the District of Columbia that were represented in this sample, 50.1\% were from California, Florida, New Jersey or Pennsylvania.

Males comprised $72.7 \%$ of the subjects $(n=51,332)$. The mean age of all subjects was 44.6 years $(\mathrm{SD}=11.8)$. Males were slightly older than females (mean $=44.9$, $\mathrm{SD}=11.6$ years $\quad$ vs. mean $=44.0, \quad \mathrm{SD}=12.2$ years; $p<.01)$. The highest percentage of subjects received care from private physical therapy practices $(53.7 \%$ of the total 
Table 2 Subject characteristics for each of the practice settings
Cells with observed frequency exceeding expected frequency are highlighted by $*(p<.01)$

\begin{tabular}{|c|c|c|c|c|c|c|c|}
\hline Characteristic & $\begin{array}{l}\text { Physician } \\
\text { offices }\end{array}$ & $\begin{array}{l}\text { Corporate } \\
\text { physical } \\
\text { therapy } \\
\text { clinics }\end{array}$ & $\begin{array}{l}\text { Occupational } \\
\text { medicine }\end{array}$ & $\begin{array}{l}\text { Hospital- } \\
\text { based }\end{array}$ & $\begin{array}{l}\text { Private } \\
\text { physical } \\
\text { therapy } \\
\text { practices }\end{array}$ & Total & \\
\hline \multirow[t]{2}{*}{ Gender } & Male & 3,621 & 15,744 & 2,449 & $1,738^{*}$ & $27,616^{*}$ & 51,168 \\
\hline & Female & $1,478^{*}$ & 5,875 & $1,079 *$ & 587 & 10,119 & 19,138 \\
\hline \multirow{5}{*}{$\begin{array}{l}\text { Age group } \\
\text { (years) }\end{array}$} & $18-30$ & 725 & 3,104 & $696^{*}$ & $404 *$ & $5,297 *$ & 10,226 \\
\hline & $31-40$ & 1,022 & 4,551 & $878^{*}$ & 473 & $8,072 *$ & 14,996 \\
\hline & $41-50$ & 1,541 & $6,671^{*}$ & 1,029 & 674 & 11,488 & 21,403 \\
\hline & $51-60$ & $1,300^{*}$ & $5,410^{*}$ & 685 & $583 *$ & $9,448 *$ & 17,426 \\
\hline & Over 60 & $511 *$ & 1,883 & 240 & 191 & $3,430 *$ & 6,255 \\
\hline \multirow{3}{*}{$\begin{array}{l}\text { Degree of } \\
\text { chronicity } \\
\text { (days) }\end{array}$} & $\begin{array}{l}\text { Acute } \\
0-30\end{array}$ & 1,508 & $7,191^{*}$ & $2,405^{*}$ & $966^{*}$ & 10,274 & 22,344 \\
\hline & $\begin{array}{c}\text { Sub-acute } \\
31-90\end{array}$ & 1,130 & $5,561 *$ & 555 & 573 & $10,000^{*}$ & 17,819 \\
\hline & $\begin{array}{c}\text { Chronic } \\
>90\end{array}$ & $2,461^{*}$ & 8,867 & 568 & 786 & $17,461 *$ & 30,143 \\
\hline \multirow{6}{*}{$\begin{array}{l}\text { Body } \\
\text { segment } \\
\text { treated }\end{array}$} & UE & $673^{*}$ & 2,754 & 422 & $314 *$ & $5,023^{*}$ & 9,186 \\
\hline & LE & $578 *$ & $2,234^{*}$ & $430 *$ & 222 & 3,456 & 6,920 \\
\hline & Back & $1,643^{*}$ & 6,100 & $1,284^{*}$ & $739 *$ & 10,652 & 20,418 \\
\hline & Neck & $241 *$ & 740 & 58 & 45 & $1,330 *$ & 2,414 \\
\hline & Hand & $188^{*}$ & $712 *$ & $289 *$ & $95^{*}$ & 1,001 & 2,285 \\
\hline & Multiple & 1,776 & $9,079^{*}$ & 1,045 & 910 & $16,273^{*}$ & 29,083 \\
\hline \multirow{2}{*}{$\begin{array}{l}\text { Surgical } \\
\text { intervention }\end{array}$} & Yes & 1021 & $5,269^{*}$ & 142 & 386 & $9,561 *$ & 16,379 \\
\hline & No & $4,078^{*}$ & 16,350 & $3,386 *$ & $1,939^{*}$ & 28,174 & 53,927 \\
\hline \multirow{2}{*}{$\begin{array}{l}\text { Prior W/C } \\
\text { Claim }\end{array}$} & No & $4,121^{*}$ & 17,084 & 2,756 & $1,891^{*}$ & $30,926^{*}$ & 56,778 \\
\hline & Yes & 978 & $4,535^{*}$ & 772 & $434 *$ & 6,809 & 13,528 \\
\hline
\end{tabular}

sample), followed by corporate physical therapy clinics $30.7 \%$, physician offices $7.3 \%$, occupational medicine clinics $5.0 \%$, and hospital-based clinics $3.3 \%$. A total of $42.9 \%$ of subjects $(n=30,143)$ began physical therapy more than 90 days after symptom onset. The most frequent body-part (s) treated was "multiple" $(41.4 \%, \mathrm{n}=29,083)$ followed by "back" $(29.0 \%, \mathrm{n}=20,418) .23 .3 \%$ of patients $(n=16,379)$ received physical therapy following surgical intervention, and $19.2 \%(\mathrm{n}=13,528)$ had a history of a prior workers' compensation claim (Table 2).

$38.25 \% \quad(n=26,940)$ of subjects' conditions were classified as sprains or strains. $31.3 \%(n=22,090)$ were classified as arthropathy, $21.1 \%(\mathrm{n}=14,855)$ were classified as dorsopathy, and the remainder were classified as fractures or dislocations $(9.0 \% \mathrm{n}=6,322)$ or other $(0.5 \%, \mathrm{n}=360)$ (Table 3). Arthropathy was most frequently observed in those patients who received treatment to multiple body-parts, while dorsopathy most frequently observed in those patients receiving care to the back or neck. Sprains and strains were most frequently observed in the back, upper and lower extremities and hand, while fractures and dislocations were most frequently observed in the upper and lower extremities (Table 4).
Unadjusted Differences in Billing Between Practice Settings

Number of Visits per Episode

Hospital-based clinics and physician offices were not significantly different in the number of visits per episode of care. All other comparisons were different at the $p<.001$ level. Corporate physical therapy clinics had a significantly higher mean number of visits during the episode of care (mean $=13.08, \mathrm{SD}=12.73$ ) than any of the other clinical settings (Table 5). The $95 \%$-confidence intervals of the differences between corporate physical therapy clinics and other clinical settings ranged from 0.6 to 1.2 fewer visits for private physical therapy practices to 5.7-7.0 fewer visits for occupational medicine clinics.

\section{Number of Treatment Units per Episode}

Hospital-based clinics and physician offices were not significantly different in the number visits per episode of care. All other comparisons were different at the $p<.001$ level. Corporate physical therapy clinics had a significantly 
Table 3 The frequency of diagnoses using the collapsed ICD-9-CM codes for each of the practice settings

\begin{tabular}{lrrrrr}
\hline Diagnosis & $\begin{array}{l}\text { Physician } \\
\text { offices }\end{array}$ & $\begin{array}{l}\text { Corporate physical } \\
\text { therapy clinics }\end{array}$ & $\begin{array}{l}\text { Occupational } \\
\text { medicine clinics }\end{array}$ & $\begin{array}{l}\text { Hospital-based } \\
\text { clinics }\end{array}$ & $\begin{array}{l}\text { Private physical } \\
\text { therapy practices }\end{array}$ \\
\hline Arthropathy & 1,340 & $6,941^{*}$ & 566 & 677 & $\begin{array}{l}\text { Total } \\
\text { Dorsopathy }\end{array}$ \\
Sprains and strains & 926 & $4,712^{*}$ & 351 & 381 & $8,464^{*}$ \\
Fractures and dislocations & $2,434^{*}$ & 7,818 & $2,479 *$ & $1,086^{*}$ & 14,800 \\
Other & 383 & $2,049 *$ & 106 & 167 & 26,855 \\
Total & 16 & 99 & $26^{*}$ & $14 *$ & 3,038 \\
\hline
\end{tabular}

Cells with observed frequency exceeding expected frequency are highlighted by $*(p<.01)$

Table 4 The diagnostic classification X the body-part that was treated for the entire sample

\begin{tabular}{|c|c|c|c|c|c|c|c|}
\hline Diagnosis classification & Upper extremity & Lower extremity & Back & Neck & Hand & Multiple & Total \\
\hline Arthropathy & 0 & 319 & 42 & 0 & 0 & $21,627 *$ & 21,988 \\
\hline Dorsopathy & 0 & 0 & $8,217 *$ & $2,414 *$ & 0 & 4,169 & 14,800 \\
\hline Sprains and strains & $4,947 *$ & $4,833 *$ & $12,159 *$ & 0 & $2,216^{*}$ & 2,700 & 26,855 \\
\hline Fractures and dislocations & $4,194 *$ & $1764 *$ & 0 & 0 & 63 & 283 & 6,304 \\
\hline Other & 45 & 4 & 0 & 0 & 6 & $304 *$ & 359 \\
\hline Total & 9,186 & 6,920 & 20,418 & 2,414 & 2,285 & 29,083 & 70,306 \\
\hline
\end{tabular}

Cells with observed frequency exceeding expected frequency are highlighted by $*(p<.01)$

Table 5 The mean (standard deviation) for primary dependent measures over the episode of care for each of the practice settings

\begin{tabular}{lcccccrr}
\hline Practice setting & $\begin{array}{l}\text { Number } \\
\text { of cases }\end{array}$ & $\begin{array}{l}\text { Visits per } \\
\text { episode }\end{array}$ & SD & $\begin{array}{l}\text { Units per } \\
\text { episode }\end{array}$ & SD & $\begin{array}{l}\text { Physical agents/total } \\
\text { units for episode }\end{array}$ & $\begin{array}{c}\text { SD } \\
\text { Physician offices }\end{array}$ \\
Corporate physical therapy clinics & 21,099 & 10.47 & 11.29 & 42.73 & 57.17 & .34 & .24 \\
Occupational medicine clinics & 3,528 & 13.08 & 12.73 & 66.79 & 85.54 & .22 & .18 \\
Hospital-based clinics & 2,325 & 10.17 & 11.13 & 43.27 & 67.64 & .31 & .22 \\
Private physical therapy practices & 37,735 & 12.18 & 12.12 & 51.38 & 62.22 & .28 & .24 \\
Total & 70,305 & 12.00 & 12.13 & 54.17 & 69.84 & .28 & .21 \\
\hline
\end{tabular}

higher mean of units during the episode of care (mean $=66.79, \mathrm{SD}=85.54)$ than any of the other clinical settings (Table 5). The $95 \%$-confidence intervals of the differences between corporate physical therapy clinics and other clinical settings ranged from 13.7 to 17.3 fewer units for private physical therapy practices to 32.4-40.2 fewer units for occupational medicine clinics.

\section{Proportion of Units of Physical Agents to Total Units for the Episode of Care}

All comparisons were different at the $p<.001$ level. Occupational medicine clinics had the highest mean proportion of units of physical agents to total units (mean $=.41$, $\mathrm{SD}=.22$ ) Corporate physical therapy clinics had the lowest mean proportion of physical agents $($ mean $=.22, \mathrm{SD}=.18)$ followed by private physical therapy practices (mean $=.28$, $\mathrm{SD}=.22$ ). The $95 \%$-confidence intervals of the differences between occupational medicine practices and other clinical settings ranged from 0.04 to 0.07 less for physician offices to .17-.19 less for corporate physical therapy clinics (Table 5).

\section{Differences in Billing Between Practice Setting Adjusted for ICD-9-CM Codes}

\section{Number of Visits per Episode}

Corporate physical therapy clinics had a significantly higher mean number of visits during the episode of care for subjects classified as arthropathy and sprains or strains 
Table 6 The mean (standard deviation) for the primary measures by practice setting and ICD-9-CM codes

\begin{tabular}{|c|c|c|c|c|c|c|c|c|}
\hline Practice setting & Diagnosis & $\begin{array}{l}\text { Number } \\
\text { of cases }\end{array}$ & $\begin{array}{l}\text { Mean visits } \\
\text { per episode }\end{array}$ & SD & $\begin{array}{l}\text { Mean units } \\
\text { per episode }\end{array}$ & SD & $\begin{array}{l}\text { Ratio passive/ } \\
\text { total units }\end{array}$ & SD \\
\hline \multirow[t]{6}{*}{ Physician offices } & Arthropathy & 1,340 & 12.79 & 13.32 & 52.92 & 68.57 & .30 & .23 \\
\hline & Dorsopathy & 926 & 9.86 & 9.36 & 38.31 & 44.30 & .29 & .25 \\
\hline & Sprains and strains & 2,434 & 9.00 & 10.29 & 37.09 & 53.32 & .40 & .24 \\
\hline & Fractures and dislocations & 383 & 13.31 & 12.22 & 54.01 & 59.00 & .25 & .22 \\
\hline & Other & 16 & 8.19 & 7.29 & 32.06 & 35.30 & .40 & .21 \\
\hline & Total & 5,099 & 10.47 & 11.29 & 42.73 & 57.17 & .34 & .24 \\
\hline \multirow{6}{*}{$\begin{array}{l}\text { Corporate physical } \\
\text { therapy clinics }\end{array}$} & Arthropathy & 6,941 & 15.70 & 14.59 & 82.20 & 98.97 & .22 & .18 \\
\hline & Dorsopathy & 4,712 & 11.90 & 11.19 & 58.75 & 66.87 & .21 & .18 \\
\hline & Sprains and strains & 7,817 & 10.51 & 10.25 & 51.74 & 64.30 & .24 & .18 \\
\hline & Fractures and dislocations & 2,049 & 16.72 & 15.05 & 90.49 & 123.93 & .17 & .15 \\
\hline & Other & 99 & 13.18 & 11.84 & 66.49 & 69.69 & .26 & .22 \\
\hline & Total & 21,618 & 13.08 & 12.73 & 66.79 & 85.54 & .22 & .18 \\
\hline \multirow[t]{6}{*}{ Occupational medicine } & Arthropathy & 566 & 8.20 & 11.40 & 37.04 & 50.03 & .43 & .20 \\
\hline & Dorsopathy & 351 & 7.41 & 8.96 & 30.17 & 34.33 & .42 & .19 \\
\hline & Sprains and strains & 2,479 & 6.19 & 6.08 & 28.55 & 31.28 & .40 & .22 \\
\hline & Fractures and dislocations & 106 & 10.81 & 15.32 & 43.20 & 61.11 & .35 & .23 \\
\hline & Other & 26 & 5.50 & 3.71 & 22.42 & 15.96 & .37 & .19 \\
\hline & Total & 3,528 & 6.77 & 7.93 & 30.47 & 36.52 & .40 & .22 \\
\hline \multirow[t]{6}{*}{ Hospital-based } & Arthropathy & 677 & 12.16 & 12.19 & 51.17 & 64.22 & .26 & .23 \\
\hline & Dorsopathy & 381 & 10.94 & 11.49 & 46.93 & 87.16 & .26 & .24 \\
\hline & Sprains and strains & 1,086 & 7.83 & 8.98 & 32.84 & 56.66 & .36 & .23 \\
\hline & Fractures and dislocations & 167 & 15.71 & 14.43 & 70.56 & 82.97 & .19 & .19 \\
\hline & Other & 14 & 8.71 & 8.99 & 46.00 & 57.80 & .24 & .32 \\
\hline & Total & 2,325 & 10.17 & 11.13 & 43.27 & 67.64 & .30 & .24 \\
\hline \multirow{6}{*}{$\begin{array}{l}\text { Private physical } \\
\text { therapy practices }\end{array}$} & Arthropathy & 12,464 & 14.30 & 13.35 & 60.70 & 70.67 & .26 & .21 \\
\hline & Dorsopathy & 8,430 & 11.34 & 11.23 & 46.76 & 55.25 & .28 & .23 \\
\hline & Sprains and strains & 13,038 & 9.90 & 10.37 & 41.65 & 51.94 & .31 & .22 \\
\hline & Fractures and dislocations & 3,599 & 14.99 & 13.51 & 64.52 & 71.92 & .22 & .20 \\
\hline & Other & 204 & 14.03 & 13.93 & 61.65 & 75.77 & .31 & .22 \\
\hline & Total & 37,735 & 12.18 & 12.11 & 51.37 & 62.22 & .28 & .22 \\
\hline \multirow[t]{6}{*}{ Entire sample } & Arthropathy & 21,988 & 14.43 & 13.74 & 66.11 & 80.85 & .25 & .20 \\
\hline & Dorsopathy & 14,800 & 11.33 & 11.09 & 49.66 & 59.63 & .26 & .22 \\
\hline & Sprains and strains & 26,854 & 9.57 & 10.03 & 42.61 & 55.14 & .31 & .22 \\
\hline & Fractures and dislocations & 6,304 & 15.40 & 14.05 & 72.12 & 92.60 & .21 & .19 \\
\hline & Other & 359 & 12.71 & 12.68 & 58.22 & 70.22 & .30 & .22 \\
\hline & Total & 70,305 & 12.00 & 12.13 & 54.17 & 69.84 & .27 & .21 \\
\hline
\end{tabular}

compared to the other clinical settings (Table 6). The $95 \%$-confidence intervals of the differences between corporate clinics and other clinical settings for arthropathy ranged from 0.80 to 2.06 fewer visits for private physical therapy practices to $5.67-9.35$ fewer visits for occupational medicine clinics. The $95 \%$-confidence intervals of the differences between corporate clinics and other clinical settings for sprains or strains ranged from 0.17 to 1.05 fewer visits for private physical therapy practices to 3.61-5.02 fewer visits for occupational medicine clinics.
There were no significant differences between corporate physical therapy clinics, hospital-based clinics and private physical therapy practices regarding the number of visits for patients classified as dorsopathy. Each of these settings had higher means than physician offices and occupational medicine clinics. Corporate physical therapy clinics and hospital-based clinics had higher means than the other settings relative to the number of visits for patients treated for fractures or dislocations, but were not different from one another. There were no significant differences in the 
number of visits among these settings groups for patients classified as other.

\section{Number of Treatment Units per Episode}

Corporate physical therapy clinics had a significantly higher mean number of units during the episode of care for each of the ICD-9 classifications except fractures or dislocations, and other, when compared with the remaining clinical settings (Table 6). The $95 \%$-confidence intervals of the difference between corporate physical therapy clinics and other clinical settings for arthropathy ranged from 17.9 to 25.3 fewer units for private physical therapy practices to 34.4-55.9 fewer units for occupational medicine clinics. The $95 \%$ confidence intervals of the difference between corporate physical therapy clinics and other clinical settings for doropathy ranged from 2.3 to 21.7 fewer units for hospital-based clinics to 18.6-38.8 fewer units for occupational medicine clinics, while the $95 \%$ confidence intervals of the difference between corporate physical therapy clinics and other clinical settings for sprains or strains ranged from 7.7 to 12.5 fewer units for private physical therapy clinics to 19.3-27.0 fewer units for occupational medicine clinics.

Corporate physical therapy clinics and hospital-based clinics had higher means for the number of visits for patient conditions classified as fracture or dislocation but were not different from one another (Table 6). There were no significant differences in the number of units between these settings for patients classified as other.

\section{Proportion of Units of Physical Agents to Total Units}

Occupational medicine clinics and physician offices had a significantly higher proportion of units of physical agents/ total units over the episode of care for subjects' conditions classified as arthropathy, dorsopathy, or sprains or strains. Occupational medicine clinics had a significantly higher proportion of units of physical agents/total units over the episode of care for subjects classified as fractures or dislocations when compared to the other 4 clinical settings. The $95 \%$-confidence intervals of the differences between occupational medicine clinics and other clinical settings ranged from 0.07 to 0.18 less for physician offices to 0.13-0.24 less for corporate physical therapy clinics. Occupational medicine clinics and physician offices had a significantly higher proportion of units of physical agents/ total units over the episode of care for subjects' conditions classified as arthropathy, dorsopathy, or sprains strains. There were no significant differences in the proportion of units of physical agents/total units over the episode of care among groups for patients classified as other.
Corporate physical therapy clinics and private physical therapy practices had a significantly lower proportion of units of physical agents/total units over the episode of care for subject conditions classified as arthropathy. Corporate physical therapy clinics had a significantly lower proportion of units of physical agents/total units over the episode of care for subject conditions classified as dorsopathy, sprains or strains, or fractures or dislocations compared to the other practice settings (Table 6).

\section{Differences in Billing Between Practice Setting} Adjusted for Body-part Treated Surgically

\section{Number of Visits per Episode}

All comparisons were significant at the $p<.001$ level. Corporate physical therapy clinics had the highest mean number of visits during the episode of care for subjects classified as receiving rehabilitation associated with surgical treatment to the upper extremity, back, or multiple areas, compared to the other practice settings. Hospitalbased out-patient physical therapy clinics had the highest mean number of visits during the episode of care for subjects classified as receiving rehabilitation associated with surgical treatment to the lower extremity, neck, or hand compared to the other practice settings (Table 7).

\section{Number of Units per Episode}

All comparisons were significant at the $p<.001$ level. Corporate physical therapy clinics had the highest mean number of units during the episode of care for subjects classified as receiving rehabilitation associated with surgical treatment to the upper extremity, lower extremity, back, or multiple areas compared to the other practice settings. Hospital-based practices had the highest mean number of units during the episode of care for subjects classified as receiving rehabilitation associated with surgical treatment to the neck, or hand compared to the other practice settings (Table 7).

\section{Proportion of Units of Physical Agents to Total Units}

All comparisons were significant at the $p<.001$ level. Occupational medicine clinics and physician offices had a significantly higher proportion of units of physical agents/ total units over the episode of care for subjects' classified as receiving rehabilitation associated with surgical treatment to each of the body-parts, when compared to the other practice settings. Corporate physical therapy clinics and hospital-based out-patient physical therapy clinics had a significantly lower proportion of units of physical agents/ total units over the episode of care for subjects' classified 
Table 7 The mean (standard deviation) for the primary measures by practice setting and body region that was treated surgically

\begin{tabular}{|c|c|c|c|c|c|c|c|c|}
\hline Practice setting & $\begin{array}{l}\text { Body region } \\
\text { (s) treated }\end{array}$ & $\begin{array}{l}\text { Number of } \\
\text { cases }\end{array}$ & $\begin{array}{l}\text { Mean visits per } \\
\text { episode }\end{array}$ & SD & $\begin{array}{l}\text { Mean units per } \\
\text { episode }\end{array}$ & SD & $\begin{array}{l}\text { Ratio passive/ } \\
\text { total units }\end{array}$ & SD \\
\hline \multirow[t]{7}{*}{ Physician offices } & Upper extremity & 219 & 18.12 & 14.02 & 75.66 & 67.81 & .272 & .21 \\
\hline & Lower extremity & 90 & 19.14 & 18.13 & 90.93 & 107.86 & .262 & .23 \\
\hline & Back & 77 & 12.12 & 9.73 & 43.70 & 46.53 & .307 & .22 \\
\hline & Neck & 48 & 15.87 & 15.21 & 59.91 & 60.95 & .291 & .22 \\
\hline & Hand & 17 & 16.71 & 12.93 & 84.47 & 77.76 & .455 & .18 \\
\hline & Multiple & 570 & 18.41 & 16.56 & 77.46 & 86.79 & .262 & .20 \\
\hline & Total & 1,021 & 17.79 & 15.72 & 75.00 & 82.09 & .272 & .21 \\
\hline \multirow{7}{*}{$\begin{array}{l}\text { Corporate physical } \\
\text { therapy clinics }\end{array}$} & Upper extremity & 1,066 & 20.90 & 17.66 & 113.15 & 115.82 & .194 & .15 \\
\hline & Lower extremity & 497 & 20.97 & 17.30 & 123.05 & 193.68 & .152 & .15 \\
\hline & Back & 316 & 17.17 & 13.98 & 88.64 & 84.38 & .166 & .18 \\
\hline & Neck & 172 & 17.83 & 16.24 & 91.79 & 94.97 & .181 & .15 \\
\hline & Hand & 55 & 19.22 & 12.66 & 87.32 & 70.54 & .238 & .13 \\
\hline & Multiple & 3,163 & 21.86 & 17.11 & 117.46 & 118.41 & .191 & .15 \\
\hline & Total & 5,269 & 21.14 & 17.05 & 114.23 & 124.52 & .187 & .15 \\
\hline \multirow[t]{7}{*}{ Occupational medicine } & Upper extremity & 28 & 12.18 & 12.42 & 54.17 & 59.23 & .381 & .16 \\
\hline & Lower extremity & 18 & 16.78 & 15.00 & 70.72 & 64.44 & .401 & .20 \\
\hline & Back & 6 & 13.17 & 4.57 & 47.00 & 14.54 & .438 & .07 \\
\hline & Neck & 4 & 12.75 & 8.01 & 51.50 & 31.16 & .480 & .12 \\
\hline & Hand & 8 & 9.75 & 7.88 & 49.00 & 45.81 & .281 & .28 \\
\hline & Multiple & 78 & 13.24 & 10.24 & 57.52 & 51.96 & .351 & .20 \\
\hline & Total & 142 & 13.27 & 11.03 & 57.44 & 53.04 & .367 & .20 \\
\hline \multirow[t]{7}{*}{ Hospital-based } & Upper extremity & 73 & 16.19 & 13.15 & 65.63 & 62.77 & .191 & .19 \\
\hline & Lower extremity & 27 & 22.63 & 18.28 & 106.59 & 100.07 & .127 & .18 \\
\hline & Back & 19 & 14.37 & 12.62 & 54.63 & 51.14 & .218 & .21 \\
\hline & Neck & 9 & 23.00 & 18.31 & 127.77 & 136.35 & .248 & .18 \\
\hline & Hand & 8 & 24.00 & 20.73 & 103.62 & 90.07 & .293 & .16 \\
\hline & Multiple & 250 & 18.04 & 14.72 & 78.49 & 85.82 & .197 & .18 \\
\hline & Total & 386 & 18.07 & 14.88 & 78.52 & 83.77 & .195 & .18 \\
\hline \multirow{7}{*}{$\begin{array}{l}\text { Private physical therapy } \\
\text { practices }\end{array}$} & Upper extremity & 1,912 & 18.46 & 15.50 & 80.93 & 85.90 & .233 & .19 \\
\hline & Lower extremity & 789 & 18.94 & 14.77 & 80.15 & 75.26 & .198 & .18 \\
\hline & Back & 570 & 16.19 & 13.36 & 66.75 & 68.91 & .196 & .19 \\
\hline & Neck & 264 & 14.92 & 13.55 & 60.60 & 66.25 & .232 & .21 \\
\hline & Hand & 84 & 17.30 & 14.92 & 74.17 & 91.75 & .286 & .20 \\
\hline & Multiple & 5,942 & 19.30 & 15.28 & 83.42 & 84.81 & .223 & .19 \\
\hline & Total & 9,561 & 18.78 & 15.15 & 80.95 & 83.16 & .222 & .19 \\
\hline \multirow[t]{7}{*}{ Entire sample } & Upper extremity & 3,298 & 19.12 & 16.12 & 90.42 & 96.37 & .223 & .18 \\
\hline & Lower extremity & 1,421 & 19.71 & 16.01 & 96.22 & 132.72 & .187 & .18 \\
\hline & Back & 988 & 16.13 & 13.31 & 71.60 & 73.50 & .197 & .19 \\
\hline & Neck & 497 & 16.15 & 14.79 & 72.47 & 79.83 & .222 & .20 \\
\hline & Hand & 172 & 17.81 & 14.15 & 79.59 & 82.15 & .287 & .19 \\
\hline & Multiple & 10,003 & 19.98 & 15.97 & 93.52 & 98.03 & .216 & .18 \\
\hline & Total & 16,379 & 19.41 & 15.84 & 91.03 & 99.48 & .215 & .18 \\
\hline
\end{tabular}

as receiving rehabilitation associated with surgical treatment to multiple body parts, compared to the other practice settings. Corporate physical therapy clinics had a significantly lower proportion of units of physical agents/total units over the episode of care for all other body parts classified as receiving rehabilitation associated with surgical treatment, compared to the other practice settings (Table 7). 
Differences in Billing Between Practice Setting

Adjusted for Body-part Treated Non-Surgically

\section{Number of Visits per Episode}

All comparisons were significant at the $p<.001$ level. Corporate physical therapy clinics had the highest mean number of visits during the episode of care for subjects classified as receiving rehabilitation associated with nonsurgical treatment for each of the body-parts treated, compared to the other practice settings. Occupational medicine had the lowest mean number of visits for each of these conditions, compared to the other practice settings (Table 8).

\section{Number of Units per Episode}

All comparisons were significant at the $p<.001$ level. Corporate physical therapy clinics had the highest mean number of units during the episode of care for subjects classified as receiving rehabilitation associated with nonsurgical treatment for each of body-parts treated, compared to the other practice settings. Occupational medicine had the lowest mean number of visits for each of these conditions, compared to the other practice settings (Table 8).

\section{Proportion of Units of Physical Agents to Total Units}

All comparisons were significant at the $p<.001$ level. Occupational medicine clinics and physician offices had a significantly higher proportion of units of physical agents/ total units over the episode of care for subjects' classified as receiving rehabilitation associated with non-surgical treatment for the lower extremity, compared to the other practice settings. Occupational medicine clinics had a significantly higher proportion of units of physical agents/ total units over the episode of care for subjects' classified as receiving rehabilitation associated with non-surgical treatment for the upper extremity, back, neck and multiple sites, compared to the other practice settings. Hospitalbased out-patient physical therapy clinics had significantly higher proportion of units of physical agents/total units over the episode of care for subjects' classified as receiving rehabilitation associated with non-surgical treatment of the hand, compared to the other practice settings. Corporate physical therapy clinics had a significantly lower proportion of units of physical agents/total units over the episode of care for subject conditions classified as receiving rehabilitation associated with nonsurgical treatment for each of body-parts treated receiving care, compared to the other practice settings (Table 8).
Differences in Billing Between Practice Setting Based Upon Geographic Location

Patients receiving care in facilities in the mid-Atlantic and East North Central regions of the United States received significantly more visits $(95 \% \mathrm{CI}=1.67$ to 7.40 , $p<.001)$ and units $(95 \% \mathrm{CI}=7.6-46.2, p<.001)$ during the episode of care compared to other regions (Table 9). When data were adjusted for practice setting, diagnosis, body-part treated or surgical status the significance and directionality of differences were not changed.

Patients receiving care in facilities in the Pacific and New England Regions received a higher proportion of physical agents to total units (95\% CI .02-.21) during their episode of care compared to all other geographic areas. Patients receiving care in facilities in the West South Central, South Atlantic and East regions received a lower proportion of physical agents to total units (95\% CI .08-.17) during the episode of care compared to all other geographic areas. The significance and directionality of differences was not changed when data were adjusted for practice setting, diagnosis, body-part treated or surgical status.

\section{Discussion}

\section{Main Findings}

Our goal was to determine if the utilization and type of physical rehabilitation care for injured workers differed based upon the setting in which the care was provided. In the present study, numerous significance differences were identified. Utilization of physical rehabilitation treatment was significantly different among settings regardless of ICD-9-CM classification, body-part treated, surgical or non-surgical intervention, and geographic area in which treatment was provided. Patients receiving care in corporate physical therapy clinics and private physical therapy practices consistently had more visits and overall units of treatment during their episode of care than did the other practice settings addressed in this study. The exact reasons for this observation are unknown. One possible explanation is that these facilities may have typically treated patients who required more care, i.e., those with more complex and prognostically unfavorable conditions than those seen in other settings. In our sample, corporate physical therapy clinics and private physical therapy practices treated higher than expected frequencies of patients who had surgical intervention, and would likely require substantial care, compared to other settings. However, these subjects only accounted for $24.1 \%$ of the total number of subjects 
Table 8 The mean (standard deviation) for the primary measures by practice setting and body region that was treated non-surgically

\begin{tabular}{|c|c|c|c|c|c|c|c|c|}
\hline Practice setting & $\begin{array}{l}\text { Body region } \\
\text { (s) treated }\end{array}$ & $\begin{array}{l}\text { Number of } \\
\text { cases }\end{array}$ & $\begin{array}{l}\text { Mean visits per } \\
\text { episode }\end{array}$ & SD & $\begin{array}{l}\text { Mean units per } \\
\text { episode }\end{array}$ & SD & $\begin{array}{l}\text { Ratio passive/ } \\
\text { total units }\end{array}$ & $\mathrm{SD}$ \\
\hline \multirow[t]{7}{*}{ Physician offices } & Upper extremity & & & 10.31 & 37.41 & 49.10 & .380 & .232 \\
\hline & Lower extremity & 488 & 8.47 & 8.90 & 33.61 & 43.29 & .352 & .253 \\
\hline & Back & 1,566 & 8.29 & 8.94 & 34.00 & 48.34 & .385 & .257 \\
\hline & Neck & 193 & 10.22 & 9.70 & 39.39 & 41.53 & .338 & .270 \\
\hline & Hand & 171 & 8.17 & 10.16 & 34.15 & 52.89 & .437 & .269 \\
\hline & Multiple & 1,206 & 8.68 & 8.22 & 34.17 & 40.53 & .344 & .251 \\
\hline & Total & 4,078 & 8.64 & 9.00 & 34.64 & 45.54 & .368 & .254 \\
\hline \multirow{7}{*}{$\begin{array}{l}\text { Corporate physical } \\
\text { therapy clinics }\end{array}$} & Upper extremity & 1,688 & 11.71 & 10.98 & 57.57 & 64.59 & .229 & .179 \\
\hline & Lower extremity & 1,737 & 10.39 & 9.40 & 52.28 & 59.55 & .207 & .178 \\
\hline & Back & 5,784 & 9.81 & 9.13 & 47.61 & 54.67 & .232 & .189 \\
\hline & Neck & 568 & 11.83 & 9.92 & 56.90 & 64.28 & .226 & .195 \\
\hline & Hand & 657 & 9.00 & 8.00 & 42.71 & 49.24 & .311 & .177 \\
\hline & Multiple & 5,916 & 10.85 & 9.83 & 53.79 & 66.48 & .248 & .193 \\
\hline & Total & 16,350 & 10.49 & 9.60 & 51.50 & 60.98 & .238 & .189 \\
\hline \multirow[t]{7}{*}{ Occupational medicine } & Upper extremity & 394 & 7.16 & 8.64 & 32.84 & 39.82 & .405 & .219 \\
\hline & Lower extremity & 412 & 6.46 & 5.98 & 27.94 & 27.90 & .356 & .244 \\
\hline & Back & 1,278 & 6.11 & 6.39 & 27.65 & 30.17 & .409 & .220 \\
\hline & Neck & 54 & 11.17 & 16.01 & 39.50 & 51.52 & .372 & .235 \\
\hline & Hand & 281 & 5.28 & 4.40 & 25.64 & 28.71 & .428 & .233 \\
\hline & Multiple & 967 & 6.85 & 9.16 & 31.24 & 41.95 & .431 & .215 \\
\hline & Total & 3,386 & 6.50 & 7.66 & 29.34 & 35.22 & .410 & .224 \\
\hline \multirow[t]{7}{*}{ Hospital-based } & Upper extremity & 241 & 10.29 & 11.55 & 44.34 & 61.87 & .316 & .224 \\
\hline & Lower extremity & 195 & 8.43 & 8.59 & 34.11 & 41.27 & .323 & .242 \\
\hline & Back & 720 & 8.04 & 9.73 & 35.08 & 82.36 & .335 & .243 \\
\hline & Neck & 36 & 10.81 & 9.62 & 39.66 & 36.20 & .300 & .281 \\
\hline & Hand & 87 & 6.78 & 5.48 & 29.32 & 28.73 & .443 & .224 \\
\hline & Multiple & 660 & 8.77 & 8.89 & 35.94 & 40.70 & .317 & .251 \\
\hline & Total & 1,939 & 8.60 & 9.47 & 36.25 & 61.61 & .329 & .244 \\
\hline \multirow{7}{*}{$\begin{array}{l}\text { Private physical therapy } \\
\text { practices }\end{array}$} & Upper extremity & 3,111 & 10.78 & 11.77 & 46.56 & 59.50 & .295 & .217 \\
\hline & Lower extremity & 2,667 & 9.67 & 8.86 & 40.38 & 46.19 & .281 & .223 \\
\hline & Back & 10,082 & 9.39 & 9.35 & 38.71 & 44.89 & .312 & .234 \\
\hline & Neck & 1,066 & 11.64 & 12.39 & 47.64 & 60.73 & .303 & .260 \\
\hline & Hand & 917 & 8.29 & 8.64 & 33.39 & 39.32 & .361 & .240 \\
\hline & Multiple & 10,331 & 10.27 & 9.94 & 42.63 & 50.28 & .300 & .226 \\
\hline & Total & 28,174 & 9.94 & 9.94 & 41.34 & 49.40 & .304 & .230 \\
\hline \multirow[t]{7}{*}{ Entire sample } & Upper extremity & 5,888 & 10.68 & 11.29 & 48.00 & 59.71 & .291 & .214 \\
\hline & Lower extremity & 5,499 & 9.51 & 8.91 & 42.38 & 49.96 & .271 & .221 \\
\hline & Back & 19,430 & 9.16 & 9.15 & 40.12 & 49.66 & .301 & .229 \\
\hline & Neck & 1,917 & 11.52 & 11.53 & 49.17 & 59.80 & .286 & .248 \\
\hline & Hand & 2,113 & 8.04 & 8.11 & 35.15 & 42.71 & .364 & .228 \\
\hline & Multiple & 19,080 & 10.12 & 9.78 & 44.75 & 55.10 & .294 & .223 \\
\hline & Total & 53,927 & 9.74 & 9.68 & 42.98 & 53.06 & .296 & .226 \\
\hline
\end{tabular}

treated by corporate physical therapy clinics and $25.3 \%$ of the total number of subjects treated by private physical therapy practices. There were no meaningful between-group changes in our findings after the analysis was adjusted for surgical intervention. The remainder of between-setting frequencies of potential predictor variables 
Table 9 The mean (standard deviation) for the primary measures listed for practice setting and the geographic region where care was provided

\begin{tabular}{|c|c|c|c|c|c|c|c|c|}
\hline Practice setting & $\begin{array}{l}\text { Geographic } \\
\text { region }\end{array}$ & $\begin{array}{l}\text { Number } \\
\text { of cases }\end{array}$ & $\begin{array}{l}\text { Visits per } \\
\text { episode }\end{array}$ & $\mathrm{SD}$ & $\begin{array}{l}\text { Units per } \\
\text { episode }\end{array}$ & SD & $\begin{array}{l}\text { Ratio passive/ } \\
\text { total units }\end{array}$ & $\mathrm{SD}$ \\
\hline \multirow[t]{10}{*}{ Physician offices } & New England & 390 & 11.05 & 9.07 & 37.65 & 39.17 & .277 & .240 \\
\hline & Middle Atlantic & 945 & 15.13 & 16.65 & 65.93 & 83.19 & .330 & .239 \\
\hline & South Atlantic & 1,346 & 9.89 & 9.05 & 38.74 & 42.99 & .242 & .228 \\
\hline & East North Central & 47 & 13.47 & 9.84 & 68.02 & 67.53 & .276 & .250 \\
\hline & East South Central & 203 & 8.96 & 8.35 & 32.06 & 33.64 & .235 & .205 \\
\hline & West North Central & 20 & 9.75 & 8.77 & 45.65 & 51.15 & .259 & .230 \\
\hline & West South Central & 140 & 9.73 & 9.78 & 44.68 & 48.61 & .139 & .227 \\
\hline & Mountain & 31 & 13.29 & 11.40 & 60.90 & 65.42 & .375 & .282 \\
\hline & Pacific & 1,977 & 8.63 & 9.55 & 35.39 & 52.23 & .475 & .214 \\
\hline & Total & 5,099 & 10.47 & 11.29 & 42.73 & 57.17 & .349 & .249 \\
\hline \multirow{10}{*}{$\begin{array}{l}\text { Corporate physical } \\
\text { therapy clinics }\end{array}$} & New England & 1,033 & 12.37 & 11.48 & 57.03 & 69.06 & .312 & .193 \\
\hline & Middle Atlantic & 6,469 & 15.39 & 15.53 & 85.86 & 114.56 & .243 & .185 \\
\hline & South Atlantic & 6,879 & 11.34 & 9.91 & 53.66 & 59.42 & .184 & .167 \\
\hline & East North Central & 2,426 & 16.21 & 14.66 & 88.22 & 91.27 & .204 & .163 \\
\hline & East South Central & 513 & 10.64 & 9.68 & 52.20 & 62.85 & .204 & .179 \\
\hline & West North Central & 1,499 & 11.30 & 10.98 & 50.81 & 61.89 & .223 & .202 \\
\hline & West South Central & 642 & 10.81 & 10.07 & 56.26 & 62.67 & .182 & .184 \\
\hline & Mountain & 820 & 13.69 & 11.73 & 73.57 & 72.61 & .268 & .166 \\
\hline & Pacific & 1,337 & 9.38 & 8.29 & 35.11 & 43.91 & .320 & .186 \\
\hline & Total & 21,618 & 13.08 & 12.73 & 66.79 & 85.54 & .225 & .183 \\
\hline \multirow[t]{10}{*}{ Occupational medicine } & New England & 237 & 5.19 & 2.97 & 20.45 & 13.03 & .590 & .150 \\
\hline & Middle Atlantic & 347 & 12.83 & 18.76 & 52.44 & 73.58 & .478 & .161 \\
\hline & South Atlantic & 1,384 & 6.24 & 5.85 & 26.40 & 27.53 & .254 & .211 \\
\hline & East North Central & 2 & 3.00 & 1.41 & 15.50 & 10.60 & .744 & .007 \\
\hline & East South Central & 121 & 6.55 & 4.68 & 43.32 & 36.53 & .484 & .208 \\
\hline & West North Central & 28 & 8.57 & 6.65 & 28.53 & 26.63 & .268 & .243 \\
\hline & West South Central & 28 & 6.46 & 4.55 & 36.50 & 35.18 & .188 & .192 \\
\hline & Mountain & 25 & 9.16 & 8.69 & 34.20 & 32.77 & .264 & .276 \\
\hline & Pacific & 1,356 & 5.99 & 4.69 & 29.47 & 30.56 & .518 & .143 \\
\hline & Total & 3,528 & 6.77 & 7.93 & 30.47 & 36.52 & .408 & .223 \\
\hline \multirow[t]{10}{*}{ Hospital-based } & New England & 485 & 6.90 & 6.44 & 31.09 & 30.41 & .466 & .205 \\
\hline & Middle Atlantic & 545 & 13.73 & 14.21 & 61.56 & 90.30 & .238 & .220 \\
\hline & South Atlantic & 504 & 10.89 & 11.37 & 44.21 & 63.31 & .281 & .234 \\
\hline & East North Central & 115 & 9.79 & 8.39 & 30.93 & 30.14 & .233 & .254 \\
\hline & East South Central & 396 & 9.49 & 8.97 & 41.15 & 47.75 & .230 & .220 \\
\hline & West North Central & 54 & 7.50 & 6.78 & 24.98 & 30.60 & .287 & .310 \\
\hline & West South Central & 39 & 8.05 & 6.64 & 33.20 & 26.96 & .203 & .223 \\
\hline & Mountain & 38 & 7.84 & 6.23 & 27.00 & 23.01 & .325 & .237 \\
\hline & Pacific & 149 & 9.64 & 15.18 & 41.41 & 125.37 & .419 & .180 \\
\hline & Total & 2,325 & 10.17 & 11.13 & 43.27 & 67.64 & .307 & .241 \\
\hline \multirow{10}{*}{$\begin{array}{l}\text { Private physical } \\
\text { therapy practices }\end{array}$} & New England & 1,918 & 13.94 & 13.58 & 59.53 & 80.45 & .318 & .236 \\
\hline & Middle Atlantic & 7,798 & 15.74 & 16.76 & 69.11 & 83.57 & .334 & .230 \\
\hline & South Atlantic & 12,649 & 11.59 & 10.21 & 48.22 & 50.86 & .224 & .208 \\
\hline & East North Central & 1,986 & 13.08 & 12.00 & 57.24 & 67.79 & .253 & .220 \\
\hline & East South Central & 2,253 & 10.42 & 9.56 & 45.48 & 51.65 & .263 & .224 \\
\hline & West North Central & 1,558 & 12.37 & 11.95 & 51.12 & 57.99 & .262 & .220 \\
\hline & West South Central & 1,249 & 10.99 & 10.13 & 49.64 & 55.42 & .228 & .219 \\
\hline & Mountain & 2,515 & 11.43 & 10.79 & 55.49 & 64.10 & .316 & .205 \\
\hline & Pacific & 5,809 & 9.03 & 7.89 & 30.68 & 33.60 & .354 & .214 \\
\hline & Total & 37,735 & 12.18 & 12.11 & 51.37 & 62.22 & .283 & .224 \\
\hline
\end{tabular}


Table 9 continued

\begin{tabular}{|c|c|c|c|c|c|c|c|c|}
\hline Practice setting & $\begin{array}{l}\text { Geographic } \\
\text { region }\end{array}$ & $\begin{array}{l}\text { Number } \\
\text { of cases }\end{array}$ & $\begin{array}{l}\text { Visits per } \\
\text { episode }\end{array}$ & SD & $\begin{array}{l}\text { Units per } \\
\text { episode }\end{array}$ & SD & $\begin{array}{l}\text { Ratio passive/ } \\
\text { total units }\end{array}$ & SD \\
\hline \multirow[t]{10}{*}{ Total sample } & New England & 4,063 & 11.91 & 11.90 & 51.12 & 68.52 & .346 & .232 \\
\hline & Middle Atlantic & 16,104 & 15.43 & 16.24 & 75.04 & 97.66 & .297 & .218 \\
\hline & South Atlantic & 22,762 & 11.07 & 9.96 & 47.89 & 52.84 & .216 & .200 \\
\hline & East North Central & 4,576 & 14.66 & 13.50 & 73.10 & 82.19 & .227 & .195 \\
\hline & East South Central & 3,486 & 10.13 & 9.35 & 45.12 & 51.90 & .257 & .221 \\
\hline & West North Central & 3,159 & 11.73 & 11.40 & 50.29 & 59.40 & .244 & .215 \\
\hline & West South Central & 2,098 & 10.73 & 10.00 & 50.85 & 56.87 & .207 & .210 \\
\hline & Mountain & 3,429 & 11.93 & 11.02 & 59.39 & 66.32 & .305 & .199 \\
\hline & Pacific & 10,628 & 8.62 & 8.17 & 32.11 & 41.36 & .394 & .214 \\
\hline & Total & 70,305 & 12.00 & 12.13 & 54.17 & 69.84 & .277 & .219 \\
\hline
\end{tabular}

States included in each region are as follows: New England (CT, ME, MA, NH), Middle Atlantic (NJ, NY, PA), East North Central (IL, IN, MI, OH, WI), West North Central (IA, KS, MN, MO, NE, ND, SD), South Atlantic (DE, DC, FL, GA, MD, NC, SC, VA, WV), East South Central (AL, KY, MS, TN), West South Central (AR, LA, OK, TX), Mountain (AZ, CO, ID, MT, NV, NM, UT, WY), Pacific (AL, CA, HA, OR, WA)

(Table 2) recorded at the inception of care did not reflect meaningful differences between corporate physical therapy clinics and private physical therapy practices compared to other settings. It is not known if other patient-specific characteristics such as job description and the presence of bio-behavioral factors or other co-morbidities, that were not addressed in this study could explain the between-setting differences in physical rehabilitation utilization.

A second possible explanation for the higher number of visits and units utilized by corporate physical therapy clinics and private physical therapy practices is that more total treatment provides a more effective outcome than less overall treatment. This contention could be addressed by a comparison of outcome measures reflecting important status changes such as functional recovery and/or return to work. Unfortunately, these data were not available; therefore, no judgments may be made on the overall "value" of care between settings.

The treatment emphasis was also significantly different between settings. Occupational medicine clinics and physician offices had higher proportions of physical agents to total units than did other settings. This finding remained consistent after the analyses were adjusted for body-part treated, surgical or non-surgical intervention and geographic area in which treatment was provided. The reason for this difference is unknown. Although the body of supporting evidence is limited, physical agents have been primarily advocated as a means to control pain in people with acute injuries [22]. The majority of patients seen in occupational medicine clinics $(68.2 \%)$ received care within 30 days of injury, which may explain the higher usage of physical agents in this setting. However, physician offices had a predominance of patients with more chronic conditions, i.e., greater than 90 days from injury to start of care (Table 2), and these settings had significantly higher proportions of physical agents to total units compared to corporate physical therapy clinics and private physical therapy practices. Another argument for the high usage of physical agents in occupational medicine clinics and physician offices is that these settings may use more nonphysical therapist "care-extenders" to provide treatment than do corporate physical therapy clinics or physical therapy private practices [14]. We are unable to address the issue from our dataset. Further study is needed to determine the relationship between the specific person delivering care and the type of treatment delivered.

Corporate physical therapy clinics and private physical therapy practices had significantly lower proportions of physical agents to total units compared to other settings, indicating a higher usage of therapeutic procedures that are supported by evidence-based treatment guidelines [24-34]. This finding is important because recent evidence has suggested that the early and sustained involvement of injured workers in the active process of their care, i.e., performing exercises and activities that encourage patients to move injured body-parts, may have both physiological and psychological benefits that exceed those provided by physical agents [35].

An unexpected finding was the large difference in treatment utilization between geographic regions regardless of practice setting, diagnosis, body-part treated or surgical intervention. The reason for this finding is unknown, but may reflect variations in local reimbursement policies.

\section{Practical Implications and Further Research}

The implications of our findings are that, regardless of ICD-9-CM code classification, body-part treated, and the presence of surgical or non-surgical intervention, there are 
likely to be significant differences in physical rehabilitation utilization and treatment emphasis for injured workers between practice settings. Patients treated in corporate physical therapy clinics and private physical therapy practices are likely to receive more care than those treated in occupational medicine clinics, physician offices or hospital-based outpatient clinics. Physical rehabilitation care provided in corporate physical therapy clinics and private physical therapy practices is likely to have the greatest emphasis on exercise- and manual therapy-based treatments, while care provided in occupational medicine clinics and physician offices will have a greater emphasis on the use of physical agents. These findings, although preliminary, suggest the need for stakeholders to further investigate the role of practice setting on overall costeffectiveness of physical rehabilitation provided to injured workers [2-4, 19, 36-38].

\section{Strengths and Limitations}

This study examined a large dataset representing urban, suburban and rural physical rehabilitation delivery to injured workers throughout the United States. The analysis was adequately powered to detect between-setting differences; however, there was an imbalance in frequency of subjects from different clinical settings. The majority $(84.4 \%)$ of the subjects received care from private physical therapy practices and corporate physical therapy clinics. Although definitive data are missing, we believe that this distribution of care is likely to be similar to actual clinical practice. The age, gender mix and other demographic characteristics of our sample are similar to other studies assessing care for injured workers; however, our findings can only be generalized to the population of people receiving physical rehabilitation for a musculoskeletal problem associated with a workers' compensation claim.

\section{Conclusions}

There were significant differences in billing for physical rehabilitation services between practice settings for patients receiving workers' compensation. Corporate and private physical therapy practices billed for more total visits and total units over the episode of care than did other practice settings. Corporate physical therapy clinics billed for a higher proportion of those interventions supported by evidence-based guidelines (exercise and manual therapy) than did other practice settings. Occupational medicine clinics and physician offices billed for a higher proportion of those interventions generally not supported by evidence-based guidelines (physical agents) over the course of care than did other clinics.

Acknowledgments The authors gratefully acknowledge Becky Larson, Claire Coyne, and Lindsey Rogers-Smith for their invaluable assistance on this project. This study was funded, in part, by a grant from the American Physical Therapy Association.

Open Access This article is distributed under the terms of the Creative Commons Attribution License which permits any use, distribution, and reproduction in any medium, provided the original author(s) and the source are credited.

\section{References}

1. de Boer W, Bruinvels DJ, Rijkenberg AM, Donceel P, Anema JR. Evidence-based guidelines in the evaluation of work disability: an international survey and a comparison of quality of development. BMC Pub Health. 2009;9:349.

2. Bernacki EJ. Factors influencing the cost of workers' compensation. Clin Occup Environ Med. 2004;4:249-57.

3. Green-McKenzie J. Workers' compensation costs: still a challenge. Clin Occup Environ Med. 2004;4:395-8.

4. LaDou J. Workers' compensation in the United States: cost shifting and inequities in a dysfunctional system. New Solut. 2010;20(3):291-302.

5. Jette A, Delitto A. Physical therapy treatment choices for musculoskeletal impairments. Phys Ther. 1997;77(2):145-54.

6. Atlas SJ, Tosteson TD, Blood EA, Skinner JS, Pransky GS, Weinstein JN. The impact of workers' compensation on outcomes of surgical and nonoperative therapy for patients with a lumbar disc herniation. Spine. 2010;35:89-97.

7. Jette A, Davis K. A comparison of hospital-based and private outpatient physical therapy practices. Phys Ther 1991;71.5:366375.

8. Tacci J, Webster B, Hasemi L, Christiani D. Clinical practices in the management of new onset, uncomplicated, low back workers' compensation disability claims. JOEM. 1999;41(5):397-404.

9. Ehrmann-Feldman D, Rossignol M, Abenhaim L, Gobeille D. Physician referral to physical therapy in a cohort of workers' compensation for low back pain. Phys Ther. 1996;76(2):150-6.

10. Mitchell J, Scott E. Physician ownership of physical therapy services: effects on charges, utilization, profits, and service characteristics. JAMA. 1992;268(15):2055-9.

11. Swedlow A, Johnson G, Smithline N, Milstein A. Increased costs and rates of use in the California Workers' compensation system as a result of self-referral by physicians. $\mathrm{N}$ Engl $\mathrm{J}$ Med. 1992;327:1502-6.

12. Duxbury P. The physician-owned physical therapy department. Orthop Clin North Am. 2008;39:49-53.

13. Mitchell J, Sass T. Physician ownership of ancillary services: indirect demand inducement or quality assurance? J Health Econ. 1995;14:263-89.

14. American Physical Therapy Association. Position on physicianowned physical therapy services (POPTS). Jan 2005. Accessed on July 242012 http://www.mopt.org/POPTS.pdf.

15. Mitchell J, de Lissovoy G. A comparison of resource use and cost in direct access versus physician referral episodes of physical therapy. Phys Ther. 1997;77(1):10-8.

16. Jette D, Ardleigh K, Chandler K, McShea L. Decision-making ability of physical therapists: physical therapy intervention or medical referral. Phys Ther. 2006;86(12):1619-29. 
17. Boissonnault W, Badke M, Powers J. Pursuit and implementation of hospital-based outpatient direct access to physical therapy services: an administrative case report. Phys Ther. 2010;90(1): 100-8.

18. Pendergast J, Kliethermes SA, Freburger JK, Duffy PA. A comparison of health care use for physician referred and selfreferred episodes of outpatient physical therapy. Health Services Research and Educational Trust doi: 10.1111/j.1475-6773.2011.

19. Lurie JD, Bell JE, Weinstein J. What rate of utilization is appropriate in musculoskeletal care? Clin Orthop Relat Res. 2009;467(10):2506-11.

20. Swinkels IC, Wimmers RH, Groenewegen PP, van den Bosch WJ, Dekker J, van den Ende $\mathrm{CH}$. What factors explain the number of physical therapy treatment sessions in patients referred with low back pain; a multilevel analysis. BMC Health Serv Res. 2005;5:74.

21. 2011 Current Procedural Terminology Standard Edition. Chicago, IL: American Medical Association; 2010;356-357.

22. Behrens BJ, Michlovitz S. Physical agents: theory and practice. Philadelphia: FA Davis Co.; 2006.

23. 2011 ICD-9-CM for Physicians, Vol 1, 2. Eden Prairie, MN: Ingenix; 2010.

24. Koes BW, van Tulder M, Lin CW, Macedo LG, McAuley J, Maher C. An updated overview of clinical guidelines for the management of non-specific low back pain in primary care. Eur Spine J. 2010;19(12):2075-94.

25. Bronfort G, Haas M, Evans RL, Bouter LM. Efficacy of spinal manipulation and mobilization for low back pain and neck pain: a systematic review and best evidence synthesis. Spine J. 2004;4(3):335-56.

26. van Middelkoop M, Rubinstein SM, Kuijpers T, Verhagen AP, Ostelo R, Koes BW. A systematic review on the effectiveness of physical and rehabilitation interventions for chronic non-specific low back pain. Eur Spine J. 2011;20(1):19-39.

27. Axe MJ, Fitzgerald GK, Snyder-Mackler L. Proposed practice guidelines for nonoperative anterior cruciate ligament rehabilitation of physically active individuals. J Orthop Sports Phys Ther. 2000;30(4):194-203.

28. Childs JD, Cleland JA, Elliott JM, Teyhen DS, Wainner RS, Whitman JM, et al. Neck pain: practice guidelines. J Orthop Sports Phys Ther. 2008;38(9):A1-34.

29. Delitto A, George SZ, Van Dillen LR, Whitman JM, Sowa G, Shekelle P, et al. Practice guidelines low back pain. J Orthop Sports Phys Ther. 2012;42(4):A1-57.

30. Carcia CR, Martin RL, Houck J, Wukich DK. Practice guidelines Achilles pain, stiffness, and muscle power deficits: achilles tendinitis. J Orthop Sports PhysTher. 2010;40(9):A1-26.

31. Logerstedt DS, Snyder-Mackler L, Ritter RC, Axe MJ. Practice guidelines knee pain and mobility impairments: meniscal and articular cartilage lesions. J Orthop Sports Phys Ther. 2010;40(6): A1-35.

32. Logerstedt DS, Snyder-Mackler L, Ritter RC, Axe MJ, Godges J. Practice guidelines knee stability and movement coordination impairments: knee ligament sprain. J Orthop Sports Phys Ther. 2010;40(4):A1-37.

33. Cibulka MT, White DM, Woehrle J. Practice guidelines hip pain and mobility deficits: hip osteoarthritis. J Orthop Sports Phys Ther. 2009;39(4):A1-25.

34. McPoil TG, Cornwall MW, Wukich DK. Practice guidelines heel pain-plantar fasciitis. J Orthop Sports Phys Ther. 2008;38(4): A1-18.

35. Waddell G. The Back Pain Revolution, 2nd Edition, ChurchillLivingstone, New York, NY, 2004, pp. 221-240, 349-357.

36. D' Andrea DC, Meyer JD. Workers' compensation reform. Clinics in Occupational and Environmental Medicine. 2004;4: 259-71.

37. Himmelstein J, Rest K. Working on reform: how workers' compensation medical care is affected by health care reform. Pub Health Rep. 1996;111:12-24.

38. Lemstra M, Olszynski WP. The effectiveness of standard care, early intervention, and occupational management in worker's compensation claims. Spine. 2003;28(3):299-304. 